\title{
A Study on the Affordance Factors for Enhancing Safety Behavior in Safety Education App
}

\author{
Hyeon-Gi Baek*, Tai-Hyun $\mathrm{Ha}^{* *}$
}

\begin{abstract}
This study focused on the focus group interview based on the questionnaire. Prior to the interview, we used questionnaires from the previous researchers in order to select the questionnaires and interviews of the focus group. In order to measure the possibility, which is the expression characteristic of the safety education app, the items related to cognitive, sensual, physical, and safety behaviors were used as constituent factors. And the safety education app to analyze was selected 'Water Go GO!' App developed by the National Emergency Management Agency.

The results of this study are as follows: First, the learner should help to participate in learning continuously in order to make meaningful learning activities in safety education app learning environment. Second, learners must interact with mobile devices in their apps to facilitate learning while reducing the number of factors that can interfere with learners' learning. This study is meaningful in that it can utilize this design principle as a guideline for enhancing safety behaviors.
\end{abstract}

Key words: Safety education, App, Safety behavior enhancement, Affordance, Focus group

\section{안전교육 앱에서 안전행동 증진을 위한 어포던스 요인에 관한 연구}

\author{
백현기*, 하태현**
}

요 약

본 연구는 행위자의 행동을 유도하는 특성을 뜻하는 어포던스 관점으로 학습자의 안전행동을 증진시 키는 안전교육 앱의 설계원리를 구체적으로 제시하는데 목적이 있으며, 설문조사를 기반으로 한 포커스 그룹 인터뷰를 중심으로 진행하였다. 안전교육 앱의 표현상의 특성인 어포던스를 측정하기 위하여 인지 적 어포던스, 감각적 어포던스, 물리적 어포던스, 안전행동 증진에 관한 문항을 구성요인으로 사용하여 측정문항을 구성하였으며, 분석하고자 한 안전교육 앱은 소방방재청에서 개발한 '물놀이GO!' 앱을 선정 하였다. 연구 결과 첫째, 학습자가 안전교육 앱 학습환경에서 유의미한 학습활동을 하게 하려면 지속적 으로 학습에 참여하도록 도와야 한다. 둘째, 앱에서 모바일 기기와 상호작용 하면서 학습을 촉진하면서 도 학습자의 학습을 방해할 수 있는 요소들은 줄여야 한다. 본 연구를 통해 안전교육 앱 학습환경을 구 성할 때 안전행동을 증진시키는 가이드라인으로써 본 설계원리를 활용할 수 있다.

키워드: 안전교육, 앱, 안전행동 증진, 어포던스, 포커스 그룹

Corresponding Author: Tai-Hyun Ha Received: December 10, 2016

Revised : December 26, 2016

Accepted : Decembe 30, 2016

* The Institute of Mind Humanities, Wonkwang University

Tel: +82-63-850-7062, Fax: +82-63-850-7062 email: mind946r@gmail.com

** Department of Fire Protection and Safety, Woosuk University

Tel: 063-290-1609, Fax: 063-290-1609

email: taiha04@daum.net

$\square$ This research was supported by the Ministry of Education of the Republic of Korea and the 


\section{Introduction}

Since childhood, humans need to learn how important safety and health are from home and school. To this end, the safety education should be balanced so as to be embodied through various experiential activities that are repeatedly performed, recognizing the importance of safety through systematic basic literacy and theoretical education according to the development stage of the students[1].

In order to cope with unconscious emergency situations, various realistic and practical training based on scenarios should be conducted. For this, practical experience-based safety education that can be experienced directly in the environment other than audiovisual education is needed.

It is necessary for students to have an ongoing and repetitive experience by implementing a scenario of the type of disaster that can occur in the current environment. In addition, it should be possible to respond appropriately to disasters in the unconscious state. Schools are focused on safety education to prevent and solve sudden safety accidents through education. In Piaget 's cognitive development stage, however, the starting point of thinking corresponds to a formal manipulator, starting from possibility rather than reality, and hypothetical and deductive reasoning is possible.

Therefore, it is appropriate to teach the safety habits of everyday life through the safety education contents that students are aware of and to provide education and training for students to prevent accidents. However, lack of safety education contents and

National Research Foundation of Korea (NRF-2015S1A5A8011889)

\ This paper was awarded the Excellent Paper Award at the 2016 Korea Digital Contents Society Conference, and the paper was revised and supplemented. developed contents are outdated, so students who are familiar with multimedia are boring, tired and ineffective. To prevent this, we need to develop content that requires an understanding of how users behave. An app is a multimedia application that is good for implementing such content. Safety education and app safety education apps can understand the knowledge, attitudes and behaviors of individual and group safety in daily life.

In this regard, this study intends to introduce 'affordance', which is a concept to induce behavior in safety education apps. Previous studies related to affordance are mostly focused on the field of design[2]. Especially, in the field of user - oriented design, research is being carried out to utilize digital technologies so that users can use objects more easily and intuitively. The purpose of this study is to investigate the factors of possibility to improve user's safety behavior in safety education app.

In this study, we analyzed the previous research to derive the affordance for each element and collected data by distributing the questionnaire after using the safety education app of 'Water-playing GO' in 10 educational engineering academics. After conducting the questionnaire, the focus group interview was conducted based on the questionnaire and qualitative research was conducted. Research on safety education apps is not yet in the starting phase. In order to further develop this, it is necessary to consider "affordance" to improve the safety behavior of safety education apps.

Therefore, this study classifies and applies the concept of safety to the safety education app, and discusses how to develop the safety education app in the future.

\section{Research contents}




\subsection{Promoting Safety Behavior}

A preliminary definition of safety is a state in which there is no risk by risk of occurrence or accident, and a condition without defect so that a safe state can be reached. Unsafe behaviors in behavioral science mean 'behaviors that can change the safety state due to habitual behavior to an unsafe state with respect to external stimulation, and unsafety acts[3]. In this paper, we propose a new method for the prevention of accidents.

As civilization develops in modern society, basic knowledge, function and safety consciousness that can be safely used are needed. It is important to know the level of safety consciousness. In addition, systematic safety education should be educated according to the level of safety, so safety culture can be effective and prevent accidents[4]. Improved safety awareness reduces the likelihood of accidents. Improving safety awareness reduces unintentional behavior and increases the likelihood and expectation of avoiding risk[5].

Generally, non-hazardous conditions are safe and safety is the opposite of risk. The mission to promote safety activities is ideally humanity and respect for people[6]. Morz defines 'safety as the prevention of accidents and the loss of property damage from personal injury or accident' [7].

Therefore, safety can be seen as securing the physical integrity from the disaster caused by the surrounding residential environment. And safety consciousness means safety consciousness that students can safely keep from danger and prevent accidents in daily life. Freud, the founder of psychoanalysis, said that the human mind is primarily made up of consciousness and unconsciousness, and that human behavior is not driven by the action of consciousness, but by the impulse of consciousness[8]. The accumulation of unconscious desires is harmful to mental health. And this leads to the conversion of consciousness, so the area of consciousness is maintained when the suppressed unconscious is resolved. Ultimately, a thorough safety awareness can prevent human error.

\subsection{Affordance}

The word affordance was first presented in 1979 by the American ecological psychologist James Gibson in his book, 'The Ecological Approach to Visual Perception'[9]. Gibson defined affordance as "everything that an environment surrounding a person provides and stimulates." He said that there is an affordance in everything that exists in an environment, such as a substance, an object, a place, an idea, a human being, or another animal, life, or artifact. And that everything around us has latent ambitions hidden in our unconsciousness.

Next, D. Norman[10], a scholar who mentions the concept of affordability, tended to focus on the mechanism of cognitive processes as an independent feature of the environment. He said that he changes the affordance by inference process through user's previous knowledge and experience. This Norman concept applies to the user-oriented design field.

He applied affordance to the ways of manipulating all things in contact in everyday life. Norman is looking at affordance from the point of view of helping users who interact with things perform most efficiently.

Gaver claims to design things based on the clear needs and abilities of users. Gaver[11] developed the concept of affordance by looking at "how the objects are perceived and how that perception affects culture" as characteristics of the environment related to the behavior system. He saw the concept of possibility as defined in the process of interacting with actors socially. He divides the affordance into four types. The four types are 
as follows[12].

The first is perceptible affordance. It refers to the case where there is an affordance in an object, and there is information perceived by the actor. If there is an affordance, but there is no perceptual information, this is a hidden affordance. If there is no affordance and only perceptual information exists, it is a false affordance. It refers to when making mistakes not related to things. The last case is called 'Correct Rejection' when both the acceptance and the perception information are not given. Gaver[11] looked at the information perceived by the user about the objects and the positives themselves. We classify and name the affordance through the existence of the existence of the object and the presence of the perception information.

Hartson [13] states that "The concept of affordance is an instrument that focuses on the connection of design between users, actions, and objects. The process of recognizing and acting from what a user feels shows how to learn and use things by each affordance. "In other words, Hartson focuses on what reaction process the user takes to relate to things[13].

In this study, we selected cognitive, physical, and sensual affordances among the positions classified by Hartson[13]. Hartson says in his study, "Affordance in design provides something to help users do what they want." He classified the type of affordance into cognitive affordance, physical affordance, sensory affordance, and functional affordance. Cognitive affordance is a design feature that helps you think about or know about tools. Physical acceptance is a design feature that helps physically act on a tool. Physical characteristics help physical behavior. And it is functional affordance to give purpose to such physical affordance. In other words, it helps the user to accomplish some task and achieve the goal. In the case of sensory accommodation, it relates to the sense of sight, hearing, and tactile sense that the user has.

\section{Research Method}

\subsection{Case Selection}

The safety education app used in this study was analyzed with the 'Water Go!' App developed by the National Emergency Management Agency. The app focuses on one specific type of safety and provides information on how to act through the description of characters and sentences so that young adults as well as adults can easily learn behavior tips for all ages.

\subsection{Analysis Method}

This study focused on the focus group interview based on the questionnaire. Prior to the interview, we used questionnaires from the previous researchers in order to select the questionnaires and interviews of the focus group.

First, measurement items were constructed using cognitive, sensory, and physical affordances as the constituent factors in order to measure the presentation characteristics of the safety education app.

However, Hartson's[13] design element is a methodology for designing affordances. Therefore, we designed the items by extracting factors appropriate for this study.

The items that can be characteristics of the safety education app were selected and configured. As a result, in the cognitive ambition, four items of clarity and predictability of meaning, distinction, persuasiveness of content and meaning, user centeredness, cognitive guidance and manipulability, and metaphor and metaphors about function, readability of information, In the three items including the factual form and 
the feature, functional assortment, two items of the classification system necessary for accomplishing the work, providing the necessary information, contents and information are presented.

The question about the promotion of safety behavior is discussed in Hoffman and novak [14], 'I am completely lost while using the safety education app', 'I am concentrating more on the safety education app than I expected', 'I became obsessed with what happened,' and 'I looked closely at information related to safety education apps.', and I conducted a basic questionnaire based on these 4 discussions and conducted a focus group interview.

The analysis in this study centered on the 'safety education app' screen which is deemed most important based on the safety education app page. In order to avoid the effect of order, we changed the given order according to the group. Each subject was asked to use the focus group subjects for more than 5 minutes before the focus group interview was started. The interviews were analyzed from the perspective of the acceptance, and the limit points were identified and discussed.

\section{Empirical Research through Focus Group Interview}

\subsection{Focus Group Selection and Configuration}

In this study, the focus group interview was conducted to see how the education engineering experts compared the existing safety education on the safety education app page. From a microscopic perspective, we will look at the experience with safety education apps from the perspective of professionals engaged in safety education. For this purpose, we will focus on two points in the focus group interview.

First, based on the theories on affordability and safety behavior, we will examine how users are receiving and experiencing safety education app pages. As summarized in previous studies[15], affordance and safety behaviors are important factors affecting user experience.

Second, safety education apps are still in the starting phase. I would like to pay attention to the examples of how these services are experienced by those who mainly deal with existing safety education.

In-depth interviews on focus groups were conducted with 12 students who were closely related to safety education in a total of 12 students, three elementary school students in grades 3, 4, 5, and 6 in June 2016.

The focus group interview was held in May of 2016 in the form of a 6 people meeting, and each meeting was held for 1:30 hours to 2 hours. One set of qualification assessments was assigned to six people, which were referred to Jakob Nilsen's guidelines[16].

The results of this study are summarized as follows. Prior to the focus group interview, we conducted questionnaires on the affection factors and safety behaviors in the safety education app. These surveys were not intended for quantitative analysis, but rather let them organize their own awareness of 'safety education'. The interview process was conducted semi - structured questionnaire with maximum consideration for the researchers to explain the purpose of the research and to intervene at least with the interviewees. The presented web pages were arranged wirelessly.

The interviews started by talking about the experiences of 'safety education' before the focus interview started. This was followed by a comparison with the experience of our own safety behavior and the features of the presented safety education app page. The semi - structured questions included Hartson 's type of assurance and safety behavior, and additional questions were asked according to 
the questionnaire conducted before the interview. Interviews with them were approved in advance and documented in interviews. The researchers repeatedly read this and analyzed the safety education app pages by dividing them into four types based on the interviews: cognitive affordance, sensuous affordance, functional affordance, and safety behavior.

\subsection{Results and Analysis}

'Water-Play GO' is a water play exclusive application. It is composed of safety rules when watering, life jacket, recommendation of place and finding wrong picture. One of the most important features of this application is that the behavior rules are arranged in a short sentence rather than a long sentence. And it was explained how to act around the character, so that anyone can follow the picture. In addition, it can be seen that the learned picture is applied to the wrong picture search game with explanation as it is, so that

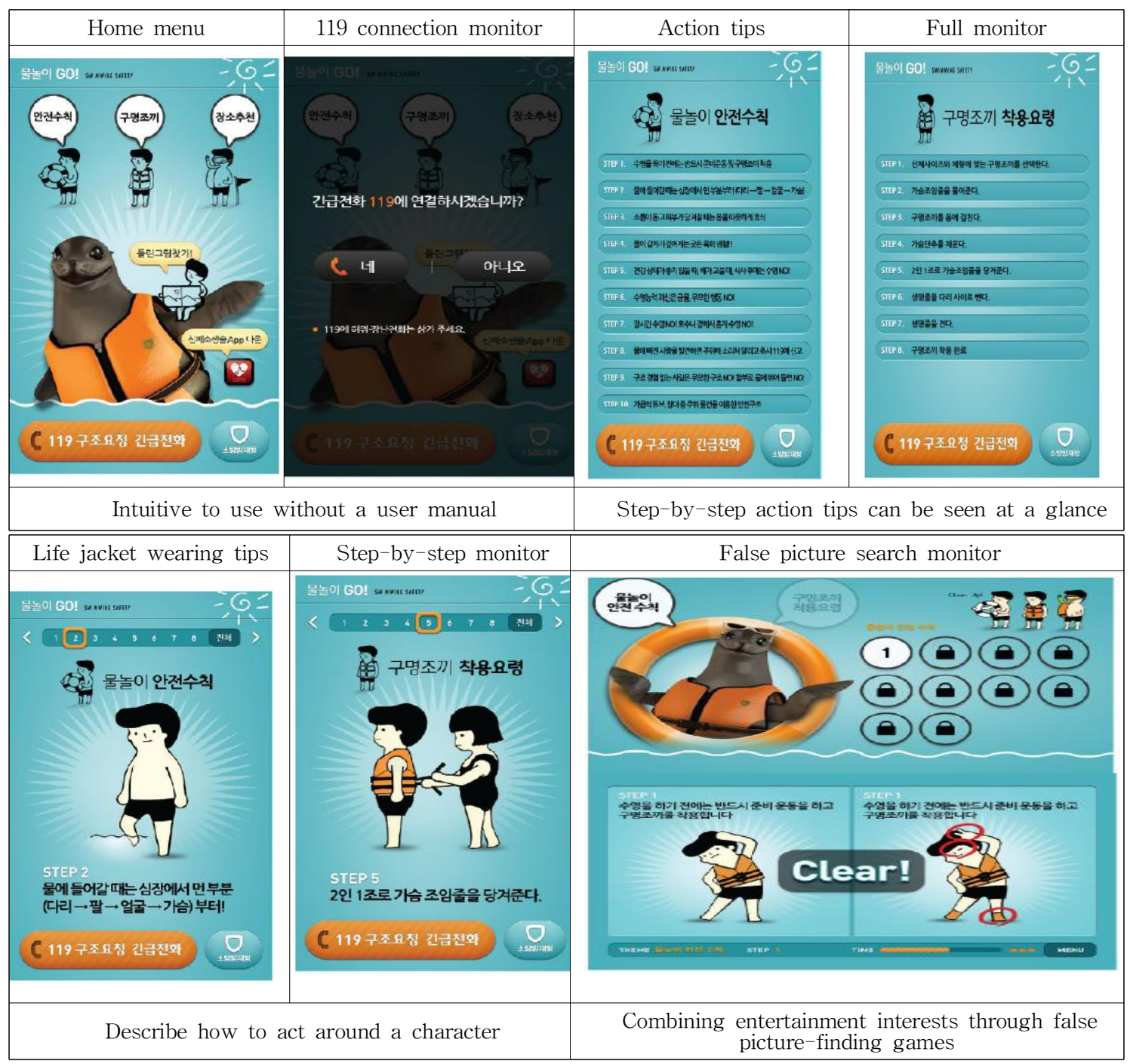

$<$ Figure 1> 'Water-play GO'Application 
the picture can be learned again.

'Water-Play GO' is a service app that allows you to download an app and cope with it whenever and wherever you want, even if you do not learn how to operate it separately.

In the question of whether the task was the same as the expected task at the time of interface operation and the task after the task performed, the accessibility using the interface and the interface part about each function were satisfactory. However, from the user's point of view, there was still a lack of sustainability and fun for macroscopic repeated learning in the safety education app.

In the case of sensual affordance, the image of the graphic is said to be most suitable for interviewers. He also said that the quality of the picture was satisfactory, and that it was suitable for exhibition with appropriate fonts.

In the case of functional affordance, there were many negative opinions about the classification system in the question about whether the classification system that is needed when the user achieves the task is well-organized. There was an opinion that the classification system is not clear compared to the amount of contents and information, and it is difficult to adapt and the system does not seem to be interesting.

In the case of safety behavior enhancement, it was suggested that users were able to observe a variety of contents during a safety training application, whether they were completely out of focus, concentrated, or meticulously reviewed necessary information or contents. Majority of participants were satisfied.

\section{Conclusion}

This study focuses on how users experience 'safety education app' through focus group interview survey, especially based on Hartson's theory of affordance and commitment. The purpose of this paper is to discuss the theoretical implications of the perspective of possibility for enhancing safety behaviors and discuss the implications and implications of applying them to safety education apps.

Based on the results of this study, we will discuss the implications of safety education app design principles from the perspective of safety to promote safety behaviors in designing safety education apps. First, in this study, safety education app should be considered before designing the safety education app. In this study, we derive an affordance that gives the meaning of safety behavior such as enhancing safety behavior.

The reason for this result is that existing safety education app designs did not properly consider the supportive elements that help the learner continue to utilize the apps provided for learning and perform meaningful learning activities within them. In order for learners to have meaningful learning activities in the safety education app learning environment, they should be encouraged to participate in learning continuously[17, 18]. Therefore, it can be said that it is meaningful in that it suggested the safety behavior improvement of the safety education app which can actually enhance the learners' participation in learning.

Second, it suggested the principles of designing safety education apps based on the perspective of perspectives to promote safety behavior. In media-based learning such as apps, learners interact with mobile devices constantly, and learning can be facilitated or interrupted depending on how they are designed[19, 20]. Considering this fact, it is suggested that the principles of safety education application design considering the possibility to improve safety behavior, so that the learner can interact with the mobile device in the app to facilitate learning while reducing 
the elements that can interfere with the learner's learning .

Therefore, if the students do not understand the media characteristics of the safety education app, they can provide the safety learning app learning environment to the learner, or if the app is provided from the same view point as e-learning, you may not feel it. In other words, it can be said that this design principle can be utilized as a guideline for enhancing safety behavior when constructing safety education app learning environment design principle can be utilized as a guideline for enhancing safety behavior when constructing safety education app learning environment. As the study of the affordance factors for the safety education presented in this study was attempted for the first time, there are limitations that can not be made more specific, whose further research is needed in the future.

\section{References}

[1] C. H. Lee. The Influence of Safety Education at Elem entary, Middle and High School on Safety Consciou sness. Ph.D dissertation, Ajou University Graduate School. 2010.

[2] J. McGrenere \& W. Ho, Affordances: Clarifying and evolving a concept. Proceedings of Graphics Interfa ce 2000, Canadian Human-Computer Communicatio ns Society, Toronto, 179-186. 2000.

[3] C. E. Chu, Prevention of unsafe behavior in PCB man ufacturing process using behavior - based approac h. Papers on Master's Degree in Chungbuk National University. 2008.

[4] Korea Occupational Safety \& Health Agency, Safety and Health Education for Secondary School Teacher s. 1994.

[5] K. H. Na, Survey of Safety Accidents and Safety
Consciousness in Middle School Chemistry Experim ent, Master's Thesis, Graduate School of Education, Korea National University of Education, 2000.

[6] P.S. Park, Industrial Safety Management. Seoul: Cen tral Economic Co Ltd. 2004.

[7] H. W. Kim, "A Study on the Development of Measur ement Scale for Safety Consciousness", Dept. of Ma ster's Degree, Graduate School, Ewha Womans Uni versity. 2002.

[8] J. I. Hyeon, \& H.C. Lee, Education dictionary. Seoul: Dongnam Planning. 2002.

[9] J. Gibson, J. J., The Ecological Approach to Visual Perception. Boston, MA: Houghton Muffin, P. 127. 1979.

[10] A. Donald, Norman, Cognitive engineering, in D. A. Norman \& S. W. Draper, User centered system design, Lawrence Erabaum Associates, Hillsdale, N J, pp. 32-33. 1986.

[11] W. W. Gaver, Technology affordances. Paper prese nted at the SIGCHI conference on Human factors in computing systems. 1991.

[12] J. McGrenere, \& W. Ho, Affordances: Clarifying an d evolving a concept, p.138, 2002.

[13] R. Hartson, Cognitive, physical, sensory, and functi onal affordances in interaction design. Behavior \& Information Technology, 22 (5), 315-338. 2003.

[14] D. Hoffman \& T. P, Novak, Marketing in Hypermed ia computer-Mediated Environments: conceptual fo undations, 1996.

[15] H.G. Baek, T.H.Ha, Study on the relationship betwe en youth smartphone addiction and personality type, Journal of Digital Convergence, 14(4), pp. 239-249, 2016

[16] D. Hoffman, Novak \& Yung, 'Measuring the Flow Construct in Online Environment; A Structural Mod 
eling Approach', Marketing Science. 19, 1998.

[17] T.H.Ha, H.G. Baek, jmA study on curing the wound ed heart applications development and effect analysi $\mathrm{s}$ by utilizing narrative therapy techniques, Journal of Digital Contents Society, 16(2), pp. 207-218, 2015

[18] H. Coates, Student engagement in campus-based and online education. New York: Routledge. 2006.

[19] T.H.Ha, H.G. Baek, A study on relationships betwe en youth smart phone addiction and mind health, an d parameter effect of school life adaption, Journal of Korean Association of Computer Education, 17( 6), pp. 147-159, 2014

[20] S. I. Park, C.I. Im, J. K. Lee, J. I. Choi, J. H. Lim, H. M. Chung, H. D. Song, S. J. Jang, K. W. Jang, J. Y. Lee, J. E. Lee, Principles and application of edu cational engineering. Seoul: Educational Science His tory. 2012.

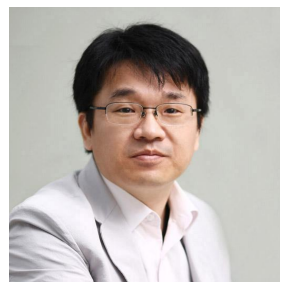

\section{Hyeon-Gi Baek}

2002.02: Woosuk University(Master of Computer Education)

2006.08: Jeonbuk National University (Doctor of Education Engineering)

$2011.03 \sim$ present : The Institute of Mind Humanities, Wonkwang University

Major interest : Affordance, Ontology, Electronic Cultural Atlasl, knowledge map, Smart-Leaming

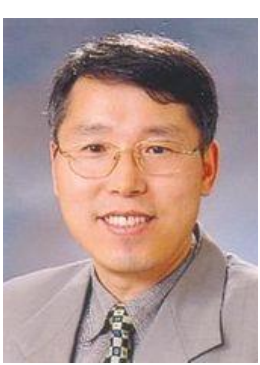

Tai-Hyun Ha

1982.02: In-Ha University(Business Administration)

1991.05: The City University (Master of Information Science)

1995.05: Swansea University (Doctor of Management Information Systems)

1997.03 2015.02 : Department of Computer Education, Woosuk University

2015.03 present : Department of Fire Protection and Safety, Woosuk University

Major interest: Affordance, Disaster management, Computer Education, Smart-Learning 